\title{
Relationship of Weight and Body Mass Index with Bone Mineral Density in Adult Men from Kosovo
}

\author{
Rexhep Hoxha', Hilmi Islami', Hasime Qorraj-Bytyqi', Shpetim Thaçi', Elton Bahtiri', \\ Department of Pharmacology, Faculty of Medicine, University of Prishtina, Kosovo \\ Department of Physiology and Immunology, Faculty of Medicine, University of Prishtina, Kosovo ${ }^{2}$ \\ Corresponding author: Elton Bahtiri, MD PhD candidate. Department of Pharmacology, Faculty of Medicine, University of Prishtina, Kosovo. Email: \\ elton.bahtiri@uni-pr.edu
}

\begin{abstract}
Background and objective: Body weight and body mass index (BMI) are considered strong predictors of osteoporotic fractures, though optimal BMI levels remain unsettled. There are several studies conducted on women about the relationship between BMI and bone mineral density (BMD), and just a few so far on men. Therefore, the objective of current study was to analyze the relationship between weight and BMI and BMD measured in lumbar spine (L1-L4), femur neck and total hip in 64 men from Kosovo. Methods: This cross-sectional study included a population of 64 men divided into three BMI groups. Dual-energy X-ray absorptiometry (DEXA) measurements were done in all the study participants. Results: Pearson's correlation analysis showed a significant positive correlation between weight and BMI and BMD in femur neck and in total hip, and a significant negative correlation between age and femur neck BMD. Age-adjusted linear regression analysis showed that weight and BMI had a significant positive association with BMD levels. Conclusion: Although the results show significant relationship between BMI and BMD, the negative relationship between age and femur neck BMD may serve as guidance to initiate early assessment of the BMD in this region as well as preventive measures of osteoporosis and fractures among ageing men population
\end{abstract}

Key words: Body mass index, weight, bone mineral density, men

\section{INTRODUCTION}

Fractures accompanying osteoporosis have become serious health problem $(1,2)$. There are many modifiable factors influencing bone mineral density (BMD), which is recognized as a surrogate marker of bone strength (3). Among them, body weight and body mass index (BMI) are considered strong predictors of osteoporotic fractures (2). Optimal BMI levels remain still unsettled, though a BMI of $26-28 \mathrm{~kg} / \mathrm{m}^{2}$ has been suggested (4). Overweight and obesity have been considered protective to bone health, while higher BMI levels to be associated with higher BMD score (5-10). Beyond the simple mechanism of mechanical load related to body weight on bone density $(2,10)$, there are some other assumed mechanisms not yet fully elucidated of interaction between adipose tissue and skeleton through several adipokines $(6,11,12,13)$. However, recent studies have questioned this traditional view concluding non-linear relationship between BMI and BMD $(10,11)$. Some studies reported no association or even lower BMD (17) or increased risk of fractures, sometimes site dependent, in obese patients (18-20).

The objective of this study was to analyze the relationship between body mass index (BMI) and weight and bone mineral density

\begin{tabular}{lllll}
\hline & $\begin{array}{l}\text { Total subjects } \\
(\mathrm{n}=64)\end{array}$ & $\begin{array}{l}\text { Normal } \\
\text { weight }(\mathrm{n}=23)\end{array}$ & $\begin{array}{l}\text { Overweight } \\
(\mathrm{n}=26)\end{array}$ & $\begin{array}{l}\text { Obesity } \\
(\mathrm{n}=15)\end{array}$ \\
\hline Age $($ years $)$ & $42.17 \pm 14.86$ & $36.30 \pm 15.81$ & $42.92 \pm 13.90$ & $49.87 \pm 11.59 \S$ \\
\hline BMI $\left(\mathrm{kg} / \mathrm{m}^{2}\right)$ & $26.69 \pm 4.97$ & $21.87 \pm 2.06$ & $27.26 \pm 1.36^{* *}$ & $33.09 \pm 4.29^{* *, 55}$ \\
\hline Height & $1.76 \pm 0.71$ & $1.77 \pm 0.69$ & $1.74 \pm 0.07$ & $1.76 \pm 0.07$ \\
\hline Weight & $82.37 \pm 16.36$ & $68.48 \pm 7.69$ & $82.80 \pm 7.06^{* *}$ & $\begin{array}{l}102.92 \pm 15.89 \\
* * \$ 5\end{array}$ \\
\hline $\begin{array}{l}\text { L1-L4 vertebrae } \\
\text { BMD }\left(\mathrm{g} / \mathrm{cm}^{2}\right)\end{array}$ & $0.995 \pm 0.136$ & $0.983 \pm 0.143$ & $0.996 \pm 0.117$ & $1.012 \pm 0.164$ \\
\hline $\begin{array}{l}\text { Femur Neck BMD } \\
\left(\mathrm{g} / \mathrm{cm}^{2}\right)\end{array}$ & $0.888 \pm 0.151$ & $0.848 \pm 0.154$ & $0.901 \pm 0.120$ & $0.927 \pm 0.191$ \\
\hline $\begin{array}{l}\text { Total Hip BMD } \\
\left(\mathrm{g} / \mathrm{cm}^{2}\right)\end{array}$ & $0.991 \pm 0.154$ & $0.936 \pm 0.145$ & $1.007 \pm 0.109$ & $1.048 \pm 0.209$ \\
\hline & & $\mathrm{n}(\%)$ & $\mathrm{n}(\%)$ & $\mathrm{n}(\%)$ \\
\hline Osteoporosis & 4 & $1(1.56)$ & $1(1.56)$ & $2(3.12)$ \\
\hline Osteopenia & 30 & $12(18.75)$ & $12(18.75)$ & $6(9.37)$ \\
\hline
\end{tabular}

Table 1. Descriptive characteristics of the study subjects. BMD bone mineral density, BMI body mass index. ${ }^{*}<0.05,{ }^{* *} p<0.01$ compared to normal weight, $\$ p<0.05$, $5 \$ p<0.01$ compared to overweight

(BMD) measured in lumbar spine (L1-L4), femur neck and total hip in a population of 64 men from Kosovo. The interest of several studies has been focused on women, but there are only few recent studies worldwide focused on this issue on men and, to our best 
knowledge, this is the first one undertaken among Kosovo men.

\section{MATERIAL AND METHODS}

\subsection{Study population}

The study population consisted of 64 men who were divided into three groups according to standard World Health Organization (WHO) Body Mass Index (BMI) classification: Normal Weight group ( $\mathrm{n}=23)$, Overweight group $(n=26)$ and Obese group $(n=15)$. Subjects were not included in the study if they had history of diseases that might affect bone metabolism or had taken drugs that might influence BMD (glucocortiocids, bisphosphonates). Written informed consent was obtained from all participants and the study protocol was approved by local Ethical Committees. The research was conducted in accordance to guidelines in Declaration of Helsinki.

\subsection{Anthropometric and bone mineral density measurements}

Height $(\mathrm{m})$ and weight $(\mathrm{kg})$ were measured in light clothing and no shoes before performing DEXA, and body mass index (BMI) was calculated as the ratio of subjects' weight to height squared $\left(\mathrm{kg} / \mathrm{m}^{2}\right)$. According to WHO criteria, participants were categorized into three BMI groups [21]: normal weight (BMI $\left.<24.9 \mathrm{~kg} / \mathrm{m}^{2}\right)$, overweight $\left(\mathrm{BMI}=25.0-29.9 \mathrm{~kg} / \mathrm{m}^{2}\right)$ and obese $\left(\mathrm{BMI}>30 \mathrm{~kg} / \mathrm{m}^{2}\right)$. Dual-energy X-ray absorptiometry (DEXA; Hologic QDR-4500, USA) was used to measure bone mineral density (BMD) in lumbar vertebrae (L1-L4), femoral neck and total hip in all study participants. DEXA was calibrated daily using a phantom provided by the manufacturer. The diagnosis of osteoporosis and osteopenia was done according to WHO T-score criteria (osteoporosis if T-score $\leq-2.5 \mathrm{SD}$, osteopenia if T-score between -2.5 SD and -1 SD, and normal BMD if Tscore $>-1 S D)$.

\begin{tabular}{llll}
\hline & Age (years) & Weight $(\mathrm{Kg})$ & $\begin{array}{l}\text { Body mass index } \\
\left(\mathrm{kg} / \mathrm{m}^{2}\right)\end{array}$ \\
\hline $\begin{array}{l}\text { L1-L4 vertebrae BMD } \\
\left(\mathrm{g} / \mathrm{cm}^{2}\right)\end{array}$ & -0.174 & 0.241 & 0.187 \\
\hline $\begin{array}{l}\text { Femur Neck BMD (g/ } \\
\left.\mathrm{cm}^{2}\right)\end{array}$ & $-0.302^{*}$ & $0.445^{* *}$ & $0.348^{* *}$ \\
\hline $\begin{array}{l}\text { Total Hip BMD } \\
\left(\mathrm{g} / \mathrm{cm}^{2}\right)\end{array}$ & -0.004 & $0.502^{* *}$ & $0.483^{* *}$ \\
\hline
\end{tabular}

Table 2. Pearson's correlation analysis between age, weight, BMI and BMD $(r){ }^{*} p<0.05 ;{ }^{* *} p<0.01$

\subsection{Statistical analysis}

SPSS version 16.0 (SPSS Inc., Chicago, IL, USA) was used for statistical analysis. All p-values in statistical analyses were two-tailed with a significance level of 0.05 . Continuous variables are expressed as the means \pm standard deviations (SD), while categorical variables as percentages. One-way analysis of variance (ANOVA) with Tukey test for Post Hoc Multiple Comparisons for continuous variables and Chi square test for categorical variables were used to compare characteristics of the three groups created on the basis of BMI. Person's correlation test was performed to assess correlation between age, weight, BMI and BMD. Age-adjusted linear regression analysis was calculated with BMI and weight as independent variables and BMD in L1-L4 vertebra, femoral neck and total hip as dependent variables.

\section{RESULTS}

Descriptive characteristics of the study population in total and according to BMI groups are summarized in Table 1 . The recruited study subjects consisted of 64 males with a mean age of $42.17 \pm 14.86(\mathrm{SD})$. There were 23 subjects ( $36.3 \pm 15.81$ years) in normal weight group, 26 subjects $(42.92 \pm 13.9$ years $)$ in overweight group and 15 subjects ( $49.87 \pm 11.59$ years) in obese group. Most men in this study were overweight or obese ( $n=41$ or $64 \%$ ).

Comparison of BMI groups by using one way ANOVA found no statistically significant difference for L1-L4 BMD, femur neck BMD and total hip BMD levels ( $p>0.05)$. Despite the fact that a statistically significant difference was not observed among BMI groups regarding BMD levels, Pearson's correlation analysis shown in table 2 reveals a significant positive correlation between weight and BMI and BMD in femur neck ( $r=0.445$, $\mathrm{p}<0.01)$ and in total hip $(\mathrm{r}=0.502, \mathrm{p}<0.01)$. No statistically significant correlation was shown between weight and BMI and L1-L4 BMD, while a significant negative correlation was observed between age and femur neck BMD $(r=-0.302, p<0.05)$.

Age-adjusted linear regression analysis showed that weight and BMI as explanatory variables had a significant positive association with L1-L4 BMD, FN BMD and TH BMD levels (Table $3)$. When weight was compared to BMI, it was observed a tendency of differences in L1-L 4 BMD and FN BMD ( $\beta=0.308$ vs. 0.305 and $\beta=0.563$ vs. $\beta=0.559)$, whereas $B M I$ showed greater difference in total hip BMD ( $\beta=0.577$ vs. 0.540$)$. Weight and $\mathrm{BMI}$ had highest squared $\mathrm{R}$ values for femur neck $\mathrm{BMD}$, where these variables can explain $38.6 \%$ and $35.4 \%$ of the variation in FN BMD $\left(\mathrm{R}^{2}=0.386\right.$ and $\mathrm{R}^{2}=0.354$, respectively $)$.

\section{DISCUSSION}

Body weight and body mass index as potentially modifiable factors are generally considered essential determinants of bone mineral density (10). Several studies demonstrated positive association of elevated body weight and/or BMI with bone mineral density or even protective effect against osteoporosis and fractures $(2,13,22)$. Principal explanation of this association was heavier mechanical loading on bones with subsequent bone remodelation to resist this loading $(2,10)$. Some of other putative mechanisms are increased estrogen synthesis (in women), increased secretion of insulin and increased plasma levels of leptin (13). However, there are other published studies focused on the impact of fat mass on BMD that demonstrated negative association of obesity with BMD; the assumed mechanisms are secretion of pro-inflammatory cytokines that stimulate bone resorption (22), decreased levels of adiponectins and increased parathormone levels $(6,12,13)$.

In accordance with results of Dogan A et al. (12), Salamat $\mathrm{M}$ et al. (9) and Lloyd J et al. (22) results of this cross-sectional 
study demonstrate a positive correlation of weight and body mass index with both femur neck BMD and total hip BMD in all male subjects included in the study, but, in contrary to them, compared to normal weight, BMD levels of overweight and obese groups were not significantly different; the lack of significant difference between BMI groups might be as limitation of the small sample size. Contrary to results of our study and above mentioned studies, Greco et al. (14) reported low lumbar BMD in obese patients, while a recent study by Emaus $\mathrm{N}$ et al. (4) demonstrated a nonlinear relationship between body mass index and bone mineral density. Every unit increase in BMI was associated with an increase of $0.008 \mathrm{~g} / \mathrm{cm}^{2}$ in L1-L $4 \mathrm{BMD}$, $0.017 \mathrm{~g} / \mathrm{cm}^{2}$ in femur neck BMD and $0.018 \mathrm{~g} / \mathrm{cm}^{2}$ in total hip $\mathrm{BMD}$. Interestingly, age was negatively correlated only with femur neck BMD in all subjects.

\section{CONCLUSION}

In conclusion, we demonstrated a highly significant relationship between body mass index and bone mineral density in femur neck and total hip in this sample of men. Negative relationship between age and femur neck BMD may serve as guidance to focus the evaluation of the bone mineral density in this region and to initiate early preventive measures of osteoporosis and fractures among aging male population.

\section{CONFLICT OF INTEREST: NONE DECLARED}

\section{REFERENCES}

1. Giusti A, Bianchi G. Male osteoporosis. Reumatismo. 2014 Jul 28; 66(2): 136-43. doi: 10.4081/reumatismo.2014.786

2. Kang D, Liu Z, Wang Y, Zhang H, Feng X, Cao W, Wang P. Relationship of body composition with bone mineral density in northern Chinese men by body mass index levels. J Endocrinol Invest. 2014 Jan 30. [Epub ahead of print]

3. Melton LJ 3rd, Beck TJ, Amin S, Khosla S, Achenbach SJ, Oberg AL, Riggs BL. Contributions of bone density and structure to fracture risk assessment in men and women. Osteoporos Int. 2005 May; 16(5): 460-467.

4. Emaus N, Wilsgaard T, Ahmed LA. Impacts of Body Mass Index, Physical Activity, and Smoking on Femoral Bone Loss. The Tromsø Study. J Bone Miner Res. 2014 Mar 28. doi: 10.1002/jbmr.2232. [Epub ahead of print]

5. Tang YJ, Sheu WH, Liu PH, Lee WJ, Chen YT. Positive associations of bone mineral density with body mass index, physical activity, and blood triglyceride level in men over 70 years old: a TCVGHAGE study. J Bone Miner Metab. 2007; 25(1): 54-59.

6. Morin S, Leslie WD; Manitoba Bone Density Program. High bone mineral density is associated with high body mass index. Osteoporos Int. 2009 Jul; 20(7): 1267-71. doi: 10.1007/s00198-008-0797-6.

7. Andreoli A, Bazzocchi A, Celi M, Lauro D, Sorge R, Tarantino U, Guglielmi G. Relationship between body composition, body mass index and bone mineral density in a large population of normal, osteopenic and osteoporotic women. Radiol Med. 2011 Oct; 116(7): 1115-1123.

8. Langsetmo L, Hitchcock CL, Kingwell EJ, Davison KS, Berger C, Forsmo S, Zhou W, Kreiger N, Prior JC; Canadian Multicentre Osteoporosis Study Research Group. Physical activity, body mass index and bone mineral density-associations in a prospective population-based cohort of women and men: the Canadian Multicentre Osteoporosis Study (CaMos). Bone. 2012 Jan; 50(1): 401-408. doi: 10.1016/j. bone.2011.11.009.

9. Salamat MR, Salamat AH, Abedi I, Janghorbani M. Relationship be- tween Weight, Body Mass Index, and Bone Mineral Density in Men Referred for Dual-Energy X-Ray Absorptiometry Scan in Isfahan, Iran. J Osteoporos. 2013; 2013: 205963. doi: 10.1155/2013/205963.

10. Wee J, Sng BY, Shen L, Lim CT, Singh G, Das De S. The relationship between body mass index and physical activity levels in relation to bone mineral density in premenopausal and postmenopausal women. Arch Osteoporos. 2013; 8(1-2): 162. doi: 10.1007/s11657-013-0162-z.

11. Russell M, Mendes N, Miller KK, Rosen CJ, Lee H, Klibanski A, Misra $\mathrm{M}$. Visceral fat is a negative predictor of bone density measures in obese adolescent girls. J Clin Endocrinol Metab. 2010 Mar; 95(3): 1247-1255. doi: 10.1210/jc.2009-1475.

12. Doğan A, Nakipoğlu-Yüzer GF, Yıldızgören MT, Ozgirgin N. Is age or the body mass index (BMI) more determinant of the bone mineral density (BMD) in geriatric women and men? Arch Gerontol Geriatr. 2010 Nov-Dec; 51(3): 338-341. doi: 10.1016/j.archger.2010.01.015.

13. Gonnelli S, Caffarelli C, Nuti R. Obesity and fracture risk. Clin Cases Miner Bone Metab. 2014 Jan; 11(1): 9-14.

14. Greco EA, Fornari R, Rossi F, Santiemma V, Prossomariti G, Annoscia C, Aversa A, Brama M, Marini M, Donini LM, Spera G, Lenzi A, Lubrano C, Migliaccio S. Is obesity protective for osteoporosis? Evaluation of bone mineral density in individuals with high body mass index. Int J Clin Pract. 2010 May; 64(6): 817-820. doi: 10.1111/j.17421241.2009.02301.x.

15. Chung W, Lee J, Ryu OH. Is the negative relationship between obesity and bone mineral content greater for olderwomen? J Bone Miner Metab. 2013 Oct 11. [Epub ahead of print]

16. Compston JE, Watts NB, Chapurlat R, Cooper C, Boonen S, Greenspan S, Pfeilschifter J, Silverman S, Díez-Pérez A, Lindsay R,Saag KG, Netelenbos JC, Gehlbach S, Hooven FH, Flahive J, Adachi JD, Rossini M, Lacroix AZ, Roux C, Sambrook PN, Siris ES; Glow Investigators. Obesity is not protective against fracture in postmenopausal women: GLOW. Am J Med. 2011 Nov; 124(11): 1043-1050. doi: 10.1016/j. amjmed.2011.06.013.

17. Paniagua MA, Malphurs JE, Samos LF. BMI and low bone mass in an elderly male nursing home population. Clin Interv Aging. 2006; 1(3): 283-287.

18. Nielson CM, Marshall LM, Adams AL, LeBlanc ES, Cawthon PM, Ensrud K, Stefanick ML, Barrett-Connor E, Orwoll ES; Osteoporotic Fractures in Men Study Research Group. BMI and fracture risk in older men: the osteoporotic fractures in men study (MrOS).J Bone Miner Res. 2011 Mar; 26(3):496-502. doi: 10.1002/jbmr.235.

19. Prieto-Alhambra D, Premaor MO, Fina Avilés F, Hermosilla E, Martinez-Laguna D, Carbonell-Abella C, Nogués X, Compston JE,DíezPérez A. The association between fracture and obesity is site-dependent: a population-based study in postmenopausal women. J Bone Miner Res. 2012 Feb; 27(2): 294-300. doi: 10.1002/jbmr.1466.

20. Premaor MO, Compston JE, Fina Avilés F, Pagès-Castellà A, Nogués X, Díez-Pérez A, Prieto-Alhambra D. The association between fracture site and obesity in men: a population-based cohort study. J Bone Miner Res. 2013 Aug; 28(8): 1771-1777. doi: 10.1002/jbmr.1878.

21. BMI classification according to WHO. Available at: http://apps.who. int/bmi/index.jsp?introPage=intro_3.html [Accessed on June 25, 2014].

22. Lloyd JT, Alley DE, Hawkes WG, Hochberg MC, Waldstein SR, Orwig DL. Body mass index is positively associated with bone mineral density in US older adults. Arch Osteoporos. 2014 Dec; 9(1): 175. doi: 10.1007/ s11657-014-0175-2. Epub 2014 Mar 25. 